\title{
Effectiveness of two physical therapy interventions, relative to dental treatment in individuals with bruxism: study protocol of a randomized clinical trial
}

Cinthia Santos Miotto Amorim ${ }^{1 *}$, Eliete Ferreira Osses Firsoff², Glauco Fioranelli Vieira ${ }^{2}$, Jecilene Rosana Costa ${ }^{3}$ and Amélia Pasqual Marques ${ }^{1}$

\begin{abstract}
Background: Bruxism is a parafunctional habit characterized by grinding and/or clenching of the teeth. It may happen while awake (awake bruxism) or while sleeping (sleep bruxism). In adults, the prevalence is 20\% for the awake bruxism and 8\% for the sleep bruxism. Peripheral, central, and psychosocial factors influence the disorder, which may predispose to pain in the masticatory muscles and neck, headache, decreased pain thresholds in the masticatory and cervical muscles, limitation mandibular range of motion, sleep disorders, stress, anxiety, depression, and overall impairment of oral health. The aim of this study is to compare two distinct physical therapy interventions with dental treatment in pain, mandibular range of motion, sleep quality, anxiety, stress, depression, and oral health in individuals with bruxism.
\end{abstract}

Methods/Design: Participants will be randomized into one of three groups: Group 1 ( $n=24)$ intervention will consist of massage and stretching exercises; Group $2(n=24)$ will consist of relaxation and imagination therapies; and Group 3 ( $n=24)$ will receive dental treatment. The evaluations will be performed at baseline, immediately after treatment, and at 2-month follow-up. Pain intensity will be assessed using the visual analogical scale, while pain thresholds will be determined using dolorimetry. Mandibular range of motion will be assessed using digital pachymeter. Sleep quality will be assessed by the Pittsburgh Sleep Quality Index, anxiety by the State-Trait Anxiety Inventory, stress by the Perceived Stress Scale-10, depression by the Beck Depression Inventory, and oral health will be assessed using the Oral Health Impact Profile - 14. Significance level will be determined at the 5\% level.

Discussion: This project describes the randomization method that will be used to compare two physical therapy interventions with dental treatment in the management of pain, mandibular range of motion, sleep quality, anxiety, stress, depression, and oral health in individuals with bruxism. The study will support the practice of evidence-based physical therapy for individuals with bruxism. Data will be published after study is completed.

Trial registration: ClinicalTrials.gov, NCT01778881

Keywords: Bruxism, Physical therapy modalities, Massage, Muscle stretching exercises, Relaxation therapy, Imagination

\footnotetext{
*Correspondence: cinthia_miotto@usp.br

'Department of Physical Therapy, Speech and Occupational Therapy, School

of Medicine, University of São Paulo, São Paulo, SP, Brazil

Full list of author information is available at the end of the article
} 


\section{Background}

The second edition of the International Classification of Sleep Disorders (ICSD-2) defines sleep bruxism as a stereotyped movement disorder characterized by grinding and/or clenching of teeth during sleep [1-5]. Awake bruxism is a semi-voluntary activity of teeth clenching that is rarely associated with audible sounds. The prevalence of awake bruxism is around 20\%, while sleep bruxism affects around $8 \%$ of adults [4-6].

Peripheral, central, and psychosocial factors are relevant to the pathophysiology of bruxism $[5,6]$, which may predispose to pain in the masticatory muscles and neck, headache, decreased pain thresholds in the masticatory and cervical muscles, limitation mandibular range of motion, sleep disorders, stress, anxiety, depression, and overall impairment of oral health. Bruxism is also associated with symptoms of other oral disorders $[2,3,5]$.

Although some studies associate bruxism with craniofacial pain, the cause-effect relationship is not yet fully established [7-9]. Pain is not present in all individuals with bruxism, but studies show that repetitive activities related to parafunctional habits are considered important factors perpetuating pain [10]. Studies indicate that clenching and/or grinding of the teeth can trigger levels of muscle sensitization post exercise in the masticatory system, leading to damage of muscle fibers and surrounding tissues $[8,11]$. Currently the focus is on adaptation model of pain, which proposes that pain arises from muscle hyperactivity and, in turn, reduces muscle activity for the protection of the masticatory system [12].

Recent international consensus formed by a group of bruxism experts affirms the bruxism can be identified by anamnesis and physical examination, and confirmed with specific questionnaires [2,5], although there is also the polysomnography conducted in sleep laboratories $[9,13]$.

Because bruxism is a multifactorial disorder, single specific treatments are not available, and multidisciplinary approaches administered by teams formed by dentists, physiotherapists, and other health professionals are often necessary [4-6]. Most treatment strategies are conservative, reversible, and symptomatic, aiming to prevent the consequences of the disorder $[5,14,15]$.

Currently, physical therapy focuses mainly in two objectives: to decrease the adverse effects of bruxism to the masticatory system, and to increase self-awareness about this parafunctional habit. Techniques include therapeutic exercises, manual therapy, cognitive behavioral therapy, electrotherapy, acupuncture, postural awareness, and muscular awareness relaxation [15-23]. Dental treatments are often necessary, whose overall goal is to reestablish the occlusal harmony [4-6]. Among the several approaches, direct restoration of the dental surface using composite resin is a good option in order to re-establish incisal guides, promoting esthetic improvement and better function and occlusion $[24,25]$.

In clinical practice, intra and extra oral massage of the masticatory muscles and massage of the cervical muscles are used and are associated with local circulation and metabolic improvements, as well as with decreasing muscle tonus [15]. Stretching exercises aim to increase mandibular range of motion, therefore decreasing pain and allowing for better mandibular rest positioning [16]. Relaxation therapies, such as progressive muscle relaxation, consist of a series of procedures involving implementation of controlled cycles of contraction and relaxation of different muscle groups. These techniques promote self-awareness of muscle tension and education on principles of muscle relaxation in activities that are relevant to normal life. Diaphragmatic breathing training and imagination (learning to create mental images of relaxed environments or activities) are relevant pieces of these therapies [18]. The literature is not clear regarding which physical therapy interventions are most effective for individuals with bruxism; therefore, more randomized controlled trials (RCTs) are necessary to clarify these questions. Moreover, little is known about the effect of two physical therapy interventions with dental treatment in individuals with bruxism.

Studies focusing physical therapy treatments to improve symptoms of bruxism such as massage of the masticatory and cervical muscles [15], stretching exercises [16], and relaxation therapies [18] are few and often do not describe in detail the treatment. Even rarer are studies that compare physical and dental therapies in individuals with bruxism [14,18]. Accordingly, our study adds to the evidence-based physical therapy practice addressing bruxism.

\section{Study aim}

The aim of this study is to compare three treatments: two distinct physical therapy interventions (massage with stretching and relaxation and imagination therapies) with dental treatment in individuals with bruxism. In particular, we aimed to focus on pain, mandibular range of motion, sleep quality, levels of anxiety, stress, and depression, as well as on the overall status of oral health.

The hypothesis of this study is that the individuals with bruxism who receive one of physical therapy interventions (massage and stretching or relaxation and imagination therapies) will have greater reduction in pain intensity levels and better mandibular range of motion, sleep quality, levels of anxiety, stress and depression, and overall status of oral health compared to individuals who receive dental treatment as assessed immediately after the 6-week physical therapy intervention and that these benefits will be maintained until reassessment 2-month follow-up. 


\section{Methods/Design}

This study will be a RCT comparing two physical therapy interventions with dental treatment. Physical therapy will last 40 minutes and will happen twice a week for 6 weeks. Sessions will be conducted by the same physical therapist. Dental treatment will consist of two individual sessions conducted 1 week apart, each of it lasting 2 hours.

\section{Enrollment and eligibility criteria}

The sample will consist of 72 patients, with established diagnosis of bruxism, that will be referred by Department of Dentistry at the School of Odontology, University of São Paulo.

\section{Inclusion criteria}

- Sleep Bruxism diagnosed according to the criteria of the International Classification for Sleep Disorders (ICSD) of the American Academy of Sleep Medicine (AASM) [1];

- Self-report of awake bruxism, documented by positive response to the question developed following the recommendations of Pintado [26];

- Aged between 18 to 60 years;

- A minimum pain intensity score of 3 on the Visual Analogical Scale [27].

\section{Exclusion criteria}

- More than two missing teeth, except third molars;

- Systemic and/or degenerative diseases;

- Arthrogenic or mixed temporomandibular disorder (TMD) according to the Research Diagnostic Criteria for Temporomandibular Disorders (RDC/TMD), axis I [28];

- Neurological or psychiatric diseases (with the exception of anxiety and depression);

- Using medications that influence sleep or motor behavior;

- Periodontal disorders;

- Abuse of alcohol and/or illicit drugs;

- Removable dentures, superior and/or inferior;

- Total dentures;

- Direct trauma or past surgery in the orofacial region;

- On physical, speech, dental, or psychological therapy at the time of study entry.

\section{Procedures}

All participants will be submitted to the same assessments, which will happen at baseline, immediately after treatment and at 2-month follow-up. Assessments will be conducted by a blinded researcher. Demographic and anthropometric data will be collected, as well as bruxism history. Examinations will also look for degree of severity of the temporomandibular disorder [29], bruxism [28,30,31], and pattern of cervical spine curvature [32]. Primary (pain and mandibular range of motion) and secondary (sleep, anxiety, stress, depression, and oral health) outcomes will be assessed.

\section{Randomization procedures}

Participants will be randomized into one of three possible groups: Group $1(n=24)$ intervention will consist of massage and stretching exercises; Group $2(n=24)$ will consist of relaxation and imagination therapies; and Group $3(n=24)$ will receive dental treatment, through a computer-generated randomization schedule that will be performed by an independent researcher, not involved in other study procedures. The allocation of participants will be concealed by using consecutive numbered, sealed, and opaque envelopes. The flow of the study is summarized in Figure 1.

\section{Outcome measures \\ Primary outcomes \\ Pain}

Pain intensity of the masseter, anterior temporalis, upper trapezius, and sternocleidomastoid muscles will be assessed using Visual Analogical Scales, constructed as a $10 \mathrm{~cm}$ ruler and clenching, muscular, and mental relaxation sensations and sleep difficulties will also be assessed using the same scale. On the left side of the scale, descriptors will be: no pain, no clenching, complete relaxation, and no difficulties falling sleep. On the right side, they will be: unbearable pain, maximum clenching, no relaxation, and being incapable of sleeping [27].

The pain threshold will be assessed using a dolorimeter with a rubber extremity with $1 \mathrm{~cm}$ of diameter. Perpendicular pressure on the skin will be applied on the trigger points of the upper trapezius, sternocleidomastoid, masseter, and anterior temporalis muscles, bilaterally. Participants will be seated straight, with feet touching the floor to the identification of the trigger points and demonstration of the dolorimeter technique in their forearm. After, patients will stay in dorsal decubitus with head discretely tilted to the opposite side of the assessments. Pain thresholds will be measured for each point, marked with a pencil. Lower thresholds are indicative of higher nociceptive sensation [33-35]. Pain thresholds will be considered positive when values are lower than $2.6 \mathrm{~kg} / \mathrm{cm}^{2}[33,36]$.

\section{Mandibular range of motion}

A digital pachymeter will be used in order to measure the mandibular range of motion (Digimess ${ }^{\oplus}$ ) [36]. Reference points will be determined using the system proposed by 


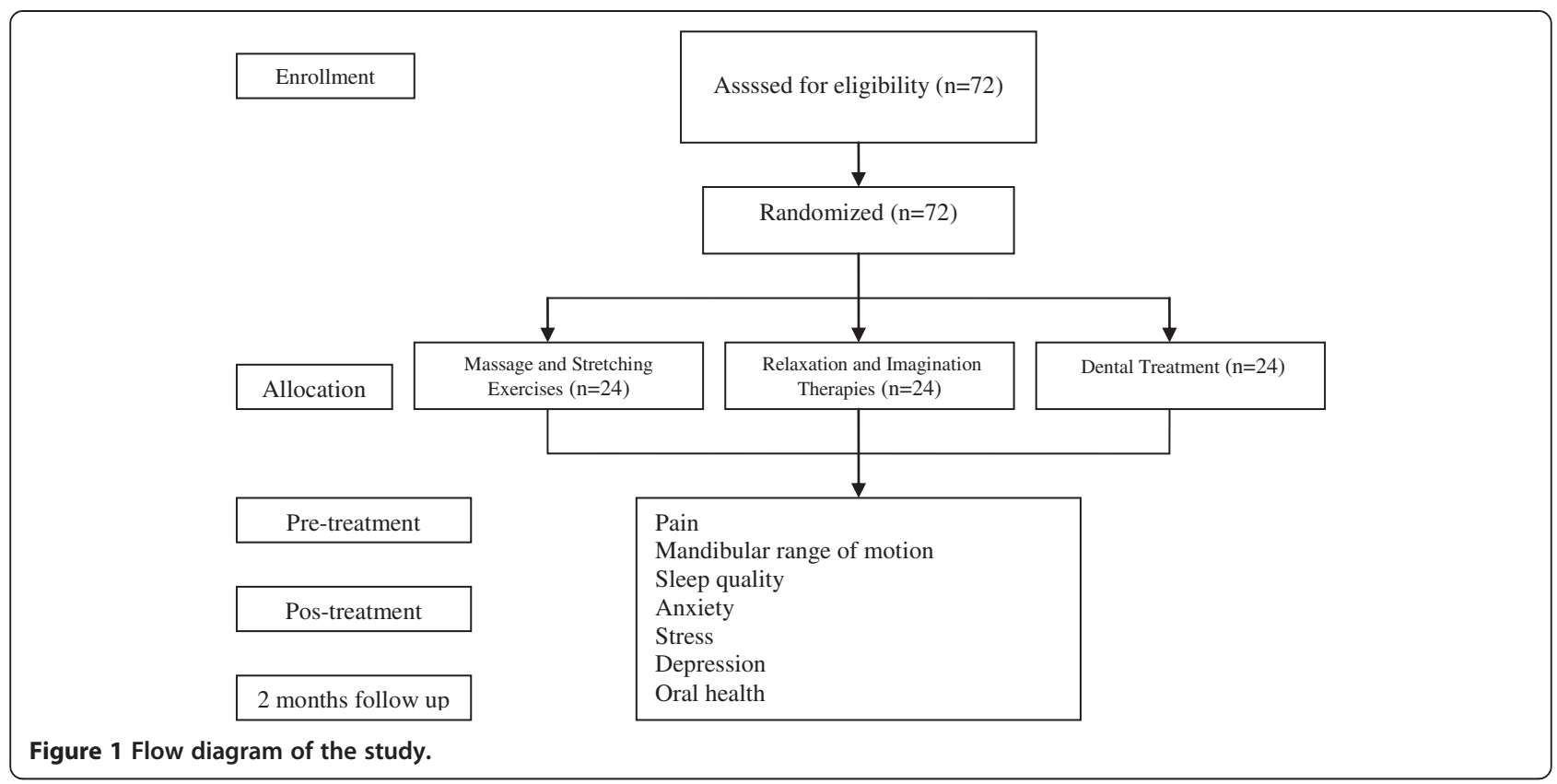

Steenks and Wijer [37], using the maximal distance between the superior and inferior incisive teeth at the incisive line, with the participant seated, with aligned spine and feet touching the floor.

\section{Secondary outcomes Quality of sleep}

Quality of sleep during the last month will be assessed using the Pittsburgh Sleep Quality Index (PSQI). This index has been translated and validated into Portuguese. It consists of 19 questions grouped under seven domains: subjective sleep quality; sleep latency; sleep duration; usual sleep efficiency; sleep disturbances; use of medications; and diurnal dysfunction. Each domain is scored (0 to 3) and a total score ( 0 to 21$)$ is calculated as follows: scores ranging from 0 to 4 are indicative of good sleep quality; scores from 5 to 10 suggest poor sleep quality; scores above 10 are suggestive of sleep disorders. Five other questions are answered by participants' spouses or partners, and further characterize sleep quality $[38,39]$.

\section{Anxiety}

Anxiety will be assessed using the State-Trait Anxiety Inventory (STAI), which has been translated and validated to the Portuguese language. It consists of two independent scales, with 20 questions each, measuring anxiety as a trait (in general) and as a state (at the moment). Each question is scored (from 1 to 4), and scores for the scales range from 20 to 80 as follows: mild anxiety (20 to 34); moderate anxiety ( 35 to 49 ); high anxiety (50 to 64 ); and very high anxiety (65 to 80$)$ [40,41].

\section{Stress}

Stress will be assessed with the Perceived Stress Scale (PSS-10), which has also been translated and validated [42]. It consists of 10 questions with scores ranging from 0 to 4 . Some questions (4, 5, 7 and 8 ) suggest absence of stress and have an inverted scoring system. Total scores range from 0 to 40 , and higher values suggest higher stress levels [43].

\section{Depression}

The Beck Depression Inventory (BDI) will be used in order to assess depression. This inventory, which has been translated and validated into Portuguese, consists of 21 groups of four statements, assessing depressive symptoms over the last week, such as hopelessness, irritability, guilt, feelings of being punished, as well as physical symptoms such as fatigue, weight loss, decreased libido. Scores below 10 suggest lack or minimal depressive symptoms; from 10 to 18 , mild to moderate depression; from 19 to 29 , moderate to severe depression; and symptoms of 30 or more are suggestive of severe depression [40].

\section{Oral health}

Oral health will be assessed using the Oral Health Impact Profile - 14, a shortened version of the Oral Health Impact Profile - 49 [44]. The questionnaire has been translated and validated into Portuguese [45]. It consists of 14 questions with five response options: (0) 
never; (1) rarely; (2) sometimes; (3) often; and (4) always. Total scores range from 0 to 56 , and higher scores are suggestive of poorer oral health [46].

\section{Intervention}

After the initial assessment, participants will receive information about bruxism, including its symptoms and consequences. They will also be educated about the study procedures. All participants will be submitted to the same assessments, at baseline, immediately after treatment, and at 2-month follow-up.

In that assessment at the 2-month follow-up, participants will receive educational material, with the purpose of providing important information about how to maintain the control of the bruxism after physical therapy interventions or dental treatment $[15,16,47]$.

\section{Group 1: massage and stretching}

The routine to be used in this group (stretching, massage, and diaphragmatic breathing) is described in Table 1 $[15,35,36,48-51]$.

\section{Group 2: relaxation and imagination therapies}

The routines to be adopted will focus on progressive muscular relaxation associated to imagination and diaphragmatic breathing. They are described in Table 2 [18,52-54].

\section{Group 3: dental treatment}

Participants in this group will be treated by a dentist, and will be submitted to the same assessments and education. Restoring treatment will involve direct reconstruction of the anterior guides (incisive faces of the incisive and canine teeth) with resin. Two individual sessions will be conducted 1 week apart, and each will last up to 2 hours. Patients will be reassessed 30, 60, and 90 days after treatment end.

\section{Sample size calculation}

Sample size was defined in order to detect a 2-point difference between groups on the pain intensity outcome measured by the Visual Analogical Scales, assuming a standard deviation of 2 points. Power was defined as $80 \%$ for an alpha of $5 \%$ and attrition (drop-outs) of $20 \%$. Accordingly, 24 participants per group will be needed.

\section{Statistical analyses}

Descriptive statistics will be used, and data will be summarized using mean, standard deviations, and percentiles. Normality of data distribution will be tested

Table 1 Description of the massage and stretching exercises

\begin{tabular}{|c|c|c|}
\hline Interventions & Description & Sets/duration \\
\hline \multirow[t]{4}{*}{ Massage } & $\begin{array}{l}\text { Patient lying supine knees semi-flexed and } \\
\text { head on pillow with proper height. }\end{array}$ & $\begin{array}{l}\text { Inspiration/Pause/Expiration: 3:3:3 seconds, } \\
\text { five sets }\end{array}$ \\
\hline & Diaphragmatic breathing training. & \\
\hline & $\begin{array}{l}\text { Extra-oral: sliding, kneading, friction, and trigger } \\
\text { points release (ischemic compression) with cream } \\
\text { and emphasis on the masseter, anterior temporalis, } \\
\text { and muscles of the neck as the upper trapezius } \\
\text { and sternocleidomastoid, bilaterally. }\end{array}$ & $\begin{array}{l}\text { Ischemic compression (maximum } 60 \text { seconds } \\
\text { with } 10 \text {-second rest between compressions), } \\
\text { five sets }\end{array}$ \\
\hline & $\begin{array}{l}\text { Intra oral: sliding, trigger points release } \\
\text { (ischemic compression), and circular and transverse } \\
\text { friction, with glove, on the masticatory muscles, } \\
\text { with emphasis on the masseter, bilaterally. }\end{array}$ & \\
\hline \multirow[t]{4}{*}{ Muscle stretching exercises } & $\begin{array}{l}\text { Patient lying supine knees semi-flexed and } \\
\text { head on pillow. }\end{array}$ & Three sets of 30 seconds \\
\hline & $\begin{array}{l}\text { Masticatory muscles: Passive exercises with the } \\
\text { help of the therapist (using gloves): elevators of the } \\
\text { jaw (masseter, temporalis and medial pterygoid), } \\
\text { retrusores (posterior temporal, digastric), lateral } \\
\text { (contralateral lateral pterygoid) and circular } \\
\text { movements of the jaw. }\end{array}$ & Intervals between sets of 10 seconds \\
\hline & Patient sitting, feet flat on the ground and spine aligned. & \\
\hline & $\begin{array}{l}\text { Muscles of the head and cervical spine: Passive } \\
\text { exercises with the help of the therapist: extensor } \\
\text { (upper trapezius, levator scapulae, suboccipital), flexor } \\
\text { (sternocleidomastoid and anterior scalene), } \\
\text { lateral flexor (sternocleidomastoid, upper trapezius, } \\
\text { middle and posterior scalenes, bilaterally), } \\
\text { and rotators (upper trapezius and } \\
\text { sternocleidomastoid contralateral), bilateral. }\end{array}$ & \\
\hline
\end{tabular}


Table 2 Description of the relaxation and imagination therapies

\begin{tabular}{|c|c|c|}
\hline Interventions & Description & Sets/duration \\
\hline \multirow[t]{6}{*}{ Progressive muscle relaxation } & Patient sitting with feet and head supported. & \multirow{3}{*}{$\begin{array}{l}\text { Inspiration/Pause/Expiration: } \\
\text { 3:3:3 seconds, five sets }\end{array}$} \\
\hline & Diaphragmatic breathing training. & \\
\hline & $\begin{array}{l}\text { First to third session: contraction and relaxation of the } \\
\text { muscle groups: arm, forearm and hands; frontal, } \\
\text { eyes and nose; mouth and jaw. }\end{array}$ & \\
\hline & $\begin{array}{l}\text { Fourth to sixth session: contraction and relaxation of the } \\
\text { muscle groups: neck; shoulder; mouth and jaw. }\end{array}$ & \multirow[t]{3}{*}{$\begin{array}{l}\text { Contraction/Relaxation: 10:20 seconds, } \\
\text { two sets of each muscle group }\end{array}$} \\
\hline & $\begin{array}{l}\text { Seventh to ninth session: repeating sequence of } \\
\text { previous sessions; }\end{array}$ & \\
\hline & $\begin{array}{l}\text { Tenth to } 12 \text { th session: complete sequence of } \\
\text { the relaxation. }\end{array}$ & \\
\hline \multirow[t]{10}{*}{ Imagination } & $\begin{array}{l}\text { Patient sitting with feet and head supported and } \\
\text { closed eyes. }\end{array}$ & \multirow[t]{10}{*}{ Three scenes (6 to 9 minutes each) } \\
\hline & $\begin{array}{l}\text { Patient in relaxation (mostly jaws) and concentration } \\
\text { in mental imagery of the scenes of your own, } \\
\text { verbally guided by the therapist, with themes such as: }\end{array}$ & \\
\hline & - Sunset & \\
\hline & - Clouds & \\
\hline & - Rivers & \\
\hline & - Flowers & \\
\hline & - Mountains & \\
\hline & - Forests & \\
\hline & - Beaches & \\
\hline & - Other & \\
\hline
\end{tabular}

using the Kolmogorov-Smirnov test. Normal variables and comparison among three groups (massage with stretching, relaxation and imagination therapies, and dental treatment) will be assessed at baseline, immediately after treatment and at 2-month follow-up using Analysis of Variance. Post-hoc tests will consist of the Turkey test for parametric variables, and the Dunn's test for non-parametric variables. Analyses will be conducted using SPSS 19 and SigmaStat 3.5. A level of significance of $5 \%$ will be used.

\section{Ethics and data security}

This trial was approved by the Ethics Committee of the School of Medicine of the University of São Paulo (protocol study - 209369/2013). All patients will be asked to provide written, informed consent prior to randomization, using standard forms. This trial is registered in ClinicalTrials.gov (a service of U.S. National Institutes of Health) under the number NCT01778881.

\section{Discussion}

The purpose of this randomized clinical trial is to compare two physical therapy interventions with dental treatment in the management of pain, mandibular range of motion, sleep quality, anxiety, stress, depression, and oral health in individuals with bruxism. The study will support the practice of evidence-based physical therapy for individuals with bruxism. Data will be published after the study is completed.

\section{Trials status}

We are currently recruiting participants.

\section{Competing interests}

The authors declare that have no competing interests.

\section{Authors' contributions}

CSMA, EFOF, GFV, JRC, and APM were responsible for the design of the study. APM will act as the study coordinators. All authors read and approved the final manuscript.

\section{Acknowledgements}

This study has Public Financial Support of National Council for Scientific and Technological Development (CNPq), Brazil. Cinthia Santos Miotto Amorim is a MsD student supported by an scholarship from the National Council for Scientific and Technological Development (CNPq), Brazil.

\section{Author details}

'Department of Physical Therapy, Speech and Occupational Therapy, School of Medicine, University of São Paulo, São Paulo, SP, Brazil. ${ }^{2}$ Department of Operative Dentistry, School of Dentistry, University of São Paulo, São Paulo, SP, Brazil. ${ }^{3}$ Department of Pediatric Otolaryngology, Federal University of São Paulo, São Paulo, SP, Brazil.

Received: 2 October 2013 Accepted: 20 December 2013

Published: 7 January 2014 


\section{References}

1. American Academy of Sleep Medicine: The International Classification of Sleep Disorders Revised: Diagnostic and Coding Manual (ICSD). 2nd edition. Chicago, IL: AASM; 2005.

2. Koyano K, Tsukiyama $Y$, Ichiki R, Kuwata T: Assessment of bruxism in the clinic. J Oral Rehabil 2008, 35:495-508.

3. Lavigne GJ, Khoury S, Abe S, Yamaguchi T, Raphael K: Bruxism physiology and pathology: an overview for clinicians. J Oral Rehabil 2008, 35:476-494.

4. Macedo CR, Silva AB, Machado MA, Saconato H, Prado GF: Occlusal splints for treating sleep bruxism (tooth grinding). Cochrane Database Syst Rev 2007, 4:CD005514

5. Shetty S, Pitti V, Satish Babu CL, Surendra Kumar GP, Deepthi BC: Bruxism: a literature review. J Indian Prosthodont Soc 2010, 10:141-148.

6. Lobbezoo F, van der Zaag J, van Selms MK, Hamburger HL, Naeije M: Principles for the management of bruxism. J Oral Rehabil 2008, 35:509-523.

7. Svensson P, Jadidi F, Arima T, Baad-Hansen L, Sessle BJ: Relationships between craniofacial pain and bruxism. J Oral Rehabil 2008, 35:524-547.

8. Lavigne GJ, Guitard F, Rompre PH, Montplaisir JY: Variability in sleep bruxism activity over time. J Sleep Res 2001, 10:237-244.

9. Van Der Zaag J, Lobbezoo F, Visscher CM, Hamburger HL, Naeije M: Time-variant nature of sleep bruxism outcome variables using ambulatory polysomnography: implications for recognition and therapy evaluation. J Oral Rehabil 2008, 35:577-584

10. Fernandes G, Franco AL, Siqueira JT, Goncalves DA, Camparis CM: Sleep bruxism increases the risk for painful temporomandibular disorder, depression and non-specific physical symptoms. J Oral Rehabil 2012 39:538-544

11. Camparis CM, Siqueira JT: Sleep bruxism: clinical aspects and characteristics in patients with and without chronic orofacial pain. Oral Surg Oral Med Oral Pathol Oral Radiol Endod 2006, 101:188-193.

12. Dawson A, Raphael KG, Glaros A, Axelsson S, Arima T, Ernberg M, Farella M, Lobbezoo F, Manfredini D, Michelotti A, Svensson P, List T: Development of a quality-assessment tool for experimental bruxism studies: reliability and validity. J Orofac Pain 2013, 27:111-122.

13. Amorim CF, Giannasi LC, Ferreira LM, Magini M, Oliveira CS, de Oliveira LV, Hirata T, Politti F: Behavior analysis of electromyographic activity of the masseter muscle in sleep bruxers. J Bodyw Mov Ther 2010, 14:234-238.

14. Alvarez-Arenal A, Junquera LM, Fernandez JP, Gonzalez I, Olay S: Effect of occlusal splint and transcutaneous electric nerve stimulation on the signs and symptoms of temporomandibular disorders in patients with bruxism. J Oral Rehabil 2002, 29:858-863.

15. Visscher CM, Lobbezoo F, Naeije M: Treatment of bruxism: physiotherapeutic approach. Ned Tijdschr Tandheelkd 2000, 107:293-296.

16. Quinn JH: Mandibular exercises to control bruxism and deviation problems. Cranio 1995, 13:30-34.

17. Knutson GA: Vectored upper cervical manipulation for chronic sleep bruxism, headache, and cervical spine pain in a child. J Manipulative Physiol Ther 2003, 26:E16.

18. Ommerborn MA, Schneider C, Giraki M, Schafer R, Handschel J, Franz M, Raab WH: Effects of an occlusal splint compared with cognitivebehavioral treatment on sleep bruxism activity. Eur J Oral Sci 2007, 115:7-14

19. Rajpurohit B, Khatri SM, Metgud D, Bagewadi A: Effectiveness of transcutaneous electrical nerve stimulation and microcurrent electrical nerve stimulation in bruxism associated with masticatory muscle paina comparative study. Indian J Dent Res 2010, 21:104-106.

20. Watanabe A, Kanemura K, Tanabe N, Fujisawa M: Effect of electromyogram biofeedback on daytime clenching behavior in subjects with masticatory muscle pain. J Prosthodont Res 2011, 55:75-81.

21. Dallanora $L$, Faltin PP, Inoue RT, Santos VM: Acunpucture use in the treatment of patients with bruxism. RGO 2004, 52:333-339.

22. Quintero Y, Restrepo CC, Tamayo V, Tamayo M, Velez AL, Gallego G, Pelaez-Vargas A: Effect of awareness through movement on the head posture of bruxist children. J Oral Rehabil 2009, 36:18-25.

23. Treacy K: Awareness/relaxation training and transcutaneous electrical neural stimulation in the treatment of bruxism. J Oral Rehabil 1999, 26:280-287.

24. Pontons-Melo JC, Furuse AY, Freitas CA, Mondelli J: Reabilitação estética e funcional da guia anterior: uma sequência lógica e conservadora. Rev dental press estét 2007, 4:39-49.
25. Pontons-Melo JC, Pizzatto E, Furuse AY, Mondelli J: A conservative approach for restoring anterior guidance: a case report. J Esthet Restor Dent 2012, 24:171-182

26. Pintado MR, Anderson GC, DeLong R, Douglas WH: Variation in tooth wear in young adults over a two-year period. J Prosthet Dent 1997, 77:313-320

27. Boonstra AM, Schiphorst Preuper HR, Reneman MF, Posthumus JB, Stewart RE: Reliability and validity of the visual analogue scale for disability in patients with chronic musculoskeletal pain. Int J Rehabil Res 2008, 31:165-169.

28. Dworkin SF, LeResche L: Research diagnostic criteria for temporomandibular disorders: review, criteria, examinations and specifications, critique. J Craniomandib Disord 1992, 6:301-355.

29. Manfredini D, Lobbezoo F: Relationship between bruxism and temporomandibular disorders: a systematic review of literature from 1998 to 2008. Oral Surg Oral Med Oral Pathol Oral Radiol Endod 2010, 109:e26-e50.

30. Pereira Júnior FJ, Favilla EE, Dworkin S, Huggins K: Critérios de diagnóstico para pesquisa das disfunções temporomandibulares (RDC/TMD). Tradução oficial para a língua portuguesa. Jornal bras clin odontol integr 2004, 8:384-395

31. Molina OF, Santos ZC, Simião BRH, Marchezan RF, e Silva NDP, Gama KR: A comprehensive method to classify subgroups of bruxers in temporomandibular disorders (TMDs) individuals: frequency, clinical and psychological implications. Revista sul brasileira de odontologia 2013, 10:11-19.

32. Lobbezoo F, Ahlberg J, Glaros AG, Kato T, Koyano K, Lavigne GJ, de Leeuw $R$, Manfredini D, Svensson P, Winocur E: Bruxism defined and graded: an international consensus. J Oral Rehabil 2013, 40:2-4

33. Marques AP, Ferreira EA, Matsutani LA, Pereira CA, Assumpcao A: Quantifying pain threshold and quality of life of fibromyalgia patients. Clin Rheumatol 2005, 24:266-271.

34. Isselee H, De Laat A, De Mot B, Lysens R: Pressure-pain threshold variation in temporomandibular disorder myalgia over the course of the menstrual cycle. J Orofac Pain 2002, 16:105-117.

35. De Laat A, Stappaerts K, Papy S: Counseling and physical therapy as treatment for myofascial pain of the masticatory system. J Orofac Pain 2003, 17:42-49.

36. Maluf SA, Moreno BG, Crivello O, Cabral CM, Bortolotti G, Marques AP. Global postural reeducation and static stretching exercises in the treatment of myogenic temporomandibular disorders: a randomized study. J Manipulative Physiol Ther 2010, 33:500-507.

37. Steenks MH, Wijer A: Disfunções da Articulação Temporomandibular do Ponto de Vista da Fisioterapia e da Odontologia - Diagnostico e Tratamento. 1st edition. Editora Santos: São Paulo; 1996

38. Bertolazi AN, Fagondes SC, Hoff LS, Dartora EG, Miozzo IC, de Barba ME, Barreto SS: Validation of the Brazilian Portuguese version of the Pittsburgh Sleep Quality Index. Sleep Med 2011, 12:70-75.

39. Buysse DJ, Reynolds CF 3rd, Monk TH, Berman SR, Kupfer DJ: The Pittsburgh Sleep Quality Index: a new instrument for psychiatric practice and research. Psychiatry Res 1989, 28:193-213.

40. Gorenstein C, Andrade L: Validation of a Portuguese version of the Beck Depression Inventory and the State-Trait Anxiety Inventory in Brazilian subjects. Braz J Med Biol Res 1996, 29:453-457.

41. Spielberger CD, Gorsuch RL, Lushene RE: Manual do Inventário de Ansiedade Traço-Estado - IDATE. Rio de Janeiro: CEPA; 1979.

42. Reis RS, Hino AA, Anez CR: Perceived stress scale: reliability and validity study in Brazil. J Health Psychol 2010, 15:107-114.

43. Cohen S, Kamarck T, Mermelstein R: A global measure of perceived stress. $J$ Health Soc Behav 1983, 24:385-396.

44. Slade GD, Spencer AJ: Development and evaluation of the Oral Health Impact Profile. Community Dent Health 1994, 11:3-11.

45. Oliveira BH, Nadanovsky P: Psychometric properties of the Brazilian version of the Oral Health Impact Profile-short form. Community Dent Oral Epidemiol 2005, 33:307-314.

46. Slade GD: Derivation and validation of a short-form oral health impact profile. Community Dent Oral Epidemiol 1997, 25:284-290.

47. Thompson BA, Blount BW, Krumholz TS: Treatment approaches to bruxism. Am Fam Physician 1994, 49:1617-1622.

48. Pierson MJ: Changes in temporomandibular joint dysfunction symptoms following massage therapy: a case report. IntJ Therapeutic Massage Bodywork 2011, 4:37-47. 
49. Capellini VK, de Souza GS, de Faria CR: Massage therapy in the management of myogenic TMD: a pilot study. J Appl Oral Sci 2006, 14:21-26.

50. Marques AP, Espírito Santos AS, Cabral CMN, Assumpcao A, Matsutani LA, Maluf SA: Movimento Articular: aspectos morfológicos e funcionais - Coluna Vertebral. Editora Manole: São Paulo; 2012.

51. Moraska AF, Hickner RC, Kohrt WM, Brewer A: Changes in blood flow and cellular metabolism at a myofascial trigger point with trigger point release (ischemic compression): a proof-of-principle pilot study. Arch Phys Med Rehabil 2013, 94:196-200.

52. Chen $Y L$, Francis AJ: Relaxation and imagery for chronic, nonmalignant pain: effects on pain symptoms, quality of life, and mental health. Pain Manag Nurs 2010, 11:159-168.

53. Kwekkeboom KL, Gretarsdottir E: Systematic review of relaxation interventions for pain. J Nurs Scholarsh 2006, 38:269-277.

54. Syrjala KL, Donaldson GW, Davis MW, Kippes ME, Carr JE: Relaxation and imagery and cognitive-behavioral training reduce pain during cancer treatment: a controlled clinical trial. Pain 1995, 63:189-198.

doi:10.1186/1745-6215-15-8

Cite this article as: Amorim et al.: Effectiveness of two physical therapy interventions, relative to dental treatment in individuals with bruxism: study protocol of a randomized clinical trial. Trials 2014 15:8.

\section{Submit your next manuscript to BioMed Central and take full advantage of:}

- Convenient online submission

- Thorough peer review

- No space constraints or color figure charges

- Immediate publication on acceptance

- Inclusion in PubMed, CAS, Scopus and Google Scholar

- Research which is freely available for redistribution 